\title{
De Digitale IVF Poli, hoe zijn we begonnen en waar
} staan we nu?

\author{
J. Schoonenberg-Pomper
}

Verpleegkundig Specialist, Polikliniek Voortplantingsgeneeskunde, UMC St Radboud, Nijmegen

\section{Samenvatting}

Op de afdeling Verloskunde en Gynaecologie van het UMC St Radboud is in 2003 de Digitale IVF Poli ontwikkeld, een via het internet benaderbaar 'persoonlijk gezondheidsdossier'. De Digitale IVF Poli is opgebouwd rond de uitgangspunten 'patient-centered care' en 'patient empowerment'. De patiënt vindt er algemene informatie, kan lotgenoten en behandelaars raadplegen op een forum en heeft toegang tot het eigen dossier. De opzet bleek zo succesvol dat zij sinds 2010 is geïntegreerd in een ruimer project, MijnZorgnet.nl, waarbinnen patiënten over heel Nederland eigen communities kunnen opzetten met medepatiënten en zorgprofessionals.

\section{Inleiding}

Het internet is in de wereld niet meer weg te denken. De mogelijkheid om informatie en kennis uit te wisselen stimuleert nieuwe ontwikkelingen in 'health promotion' en in de preventie en behandeling van medische problemen, en maakt van het internet een steeds belangrijker communicatiemiddel tussen de patiënt en de medische wereld. ${ }^{1}$

Uit een focusgroeponderzoek in 2001 op het UMC St Radboud kwam naar voren dat IVFpatiënten meer betrokken wilden worden bij de eigen behandeling. Gelijkwaardig partnerschap betekende voor hen niet alleen kennis maar ook inzage in het eigen dossier, waar- door een betere samenwerking tussen het paar en de artsen tot stand kan komen. Zo werd het idee geboren van een via het internet benaderbaar 'persoonlijk gezondheidsdossier', oftewel de Digitale IVF Poli.

Eind 2003 ontwikkelde informatiedeskundige Wouter Tuil een pilot-versie van de Digitale IVF Poli, waaraan vijf paren deelnamen. De opbouw van de digitale poli is tot op heden hetzelfde gebleven: een informatiegedeelte, een communicatiegedeelte en een eigen dossiergedeelte. In het informatiegedeelte kunnen patiënten algemene informatie vinden over een IVF- of ICSI-behandeling en specifieke informatie over de behandeling in het ziekenhuis. Het communicatiegedeelte 


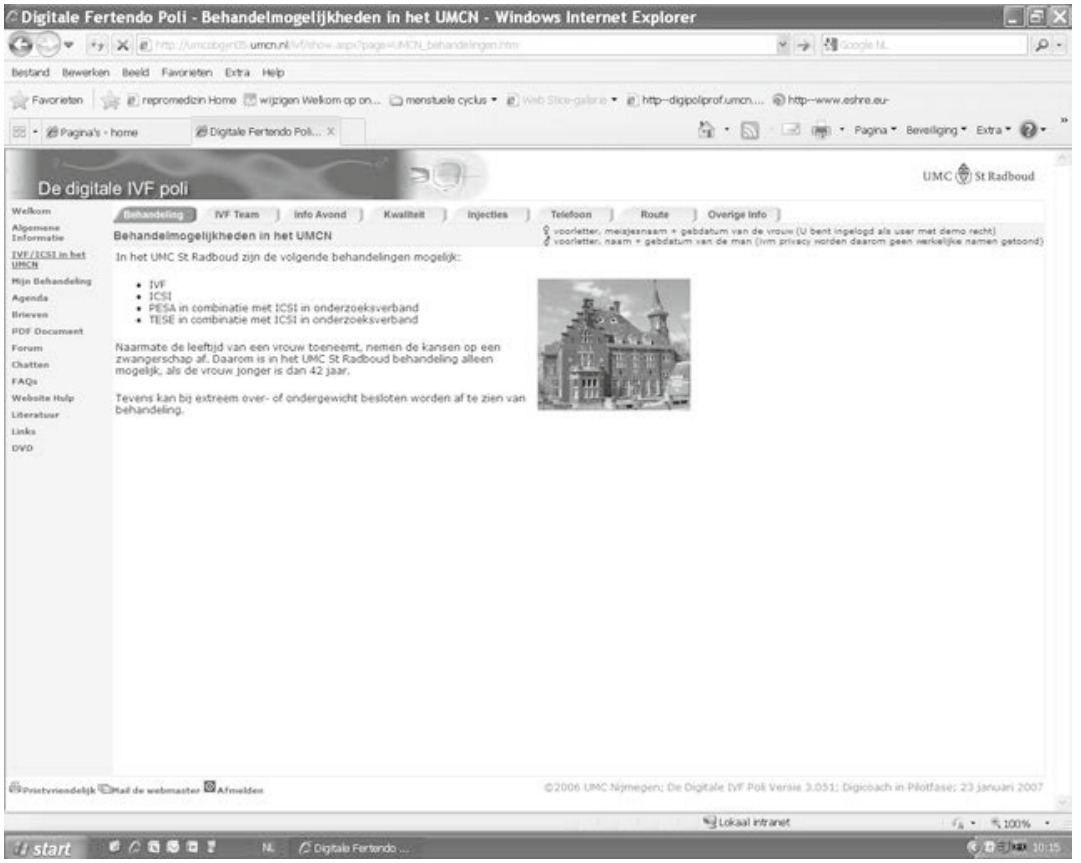

Figuur 1

Homepage van de Digitale IVF Poli.

Bron: W.S. Tuil

bestaat uit een chatroom en een forum waarop patiënten vragen kunnen stellen aan elkaar en aan het IVF-team van het UMC St Radboud.

Op het eigen dossiergedeelte hebben patiënten bij elke stap van de behandeling toegang tot resultaten zoals bloeduitslagen, opbrengst van een follikelpunctie, aantal ontstane embryo's en foto's van de geplaatste embryo's, maar ook tot de brieven van hun behandelaar aan andere zorgverleners, zoals de huisarts.

In eerste instantie leverde de Digitale IVF Poli enige weerstand op bij de professionals. Deze waren bang voor een grote toename van het aantal e-mails. Zij verwachtten ook dat patiënten elkaar angst zouden aanpraten en de hoeveelheid informatie niet aan zouden kunnen. Deze vrees werd echter niet bewaarheid en eind 2004 besloot de afdeling Verloskunde en Gynaecologie van UMC St Radboud de Digitale IVF Poli op te nemen in het reguliere zorgaanbod.
'Patient-centered care' en 'patient empowerment'

De kwaliteit van de gezondheidszorg heeft zes dimensies: veiligheid, effectiviteit, 'patient-centeredness', opportuniteit, efficiëntie en gelijkheid. 'Patient-centered care' is zorg die rekening houdt met het individu, met diens normen en waarden, afkomst, sociale status en behoefte aan informatie. ${ }^{3}$

'Patient empowerment' betekent dat de zorgverlener de patiënt inlicht over diens gezondheidsstatus en hem leert een actieve rol te vervullen in beslissingen rondom de eigen behandeling. ' 'Patient empowerment' brengt een significante verbetering in het psychosociale aspect van het omgaan met een ziekte. ${ }^{5}$

De Digitale IVF Poli is opgebouwd rond de uitgangspunten 'patient-centered care' en 'patient empowerment'. De effecten op 'patient empowerment' en op patiënttevredenheid zijn onderzocht, maar waren door het kleine aantal deenemers in de beginfase moeilijk te bewijzen. Bij de deelnemers zijn 


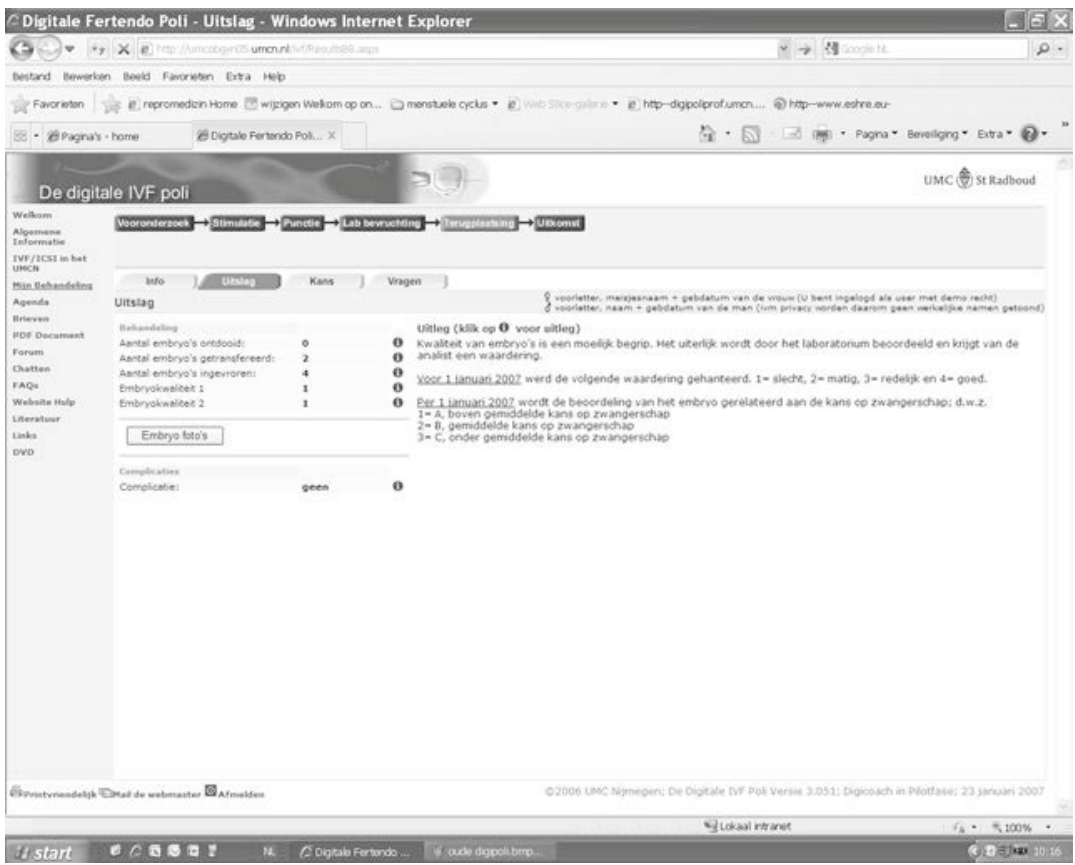

\section{Figuur 2}

Het eigen dossier.

Bron: W.S. Tuil

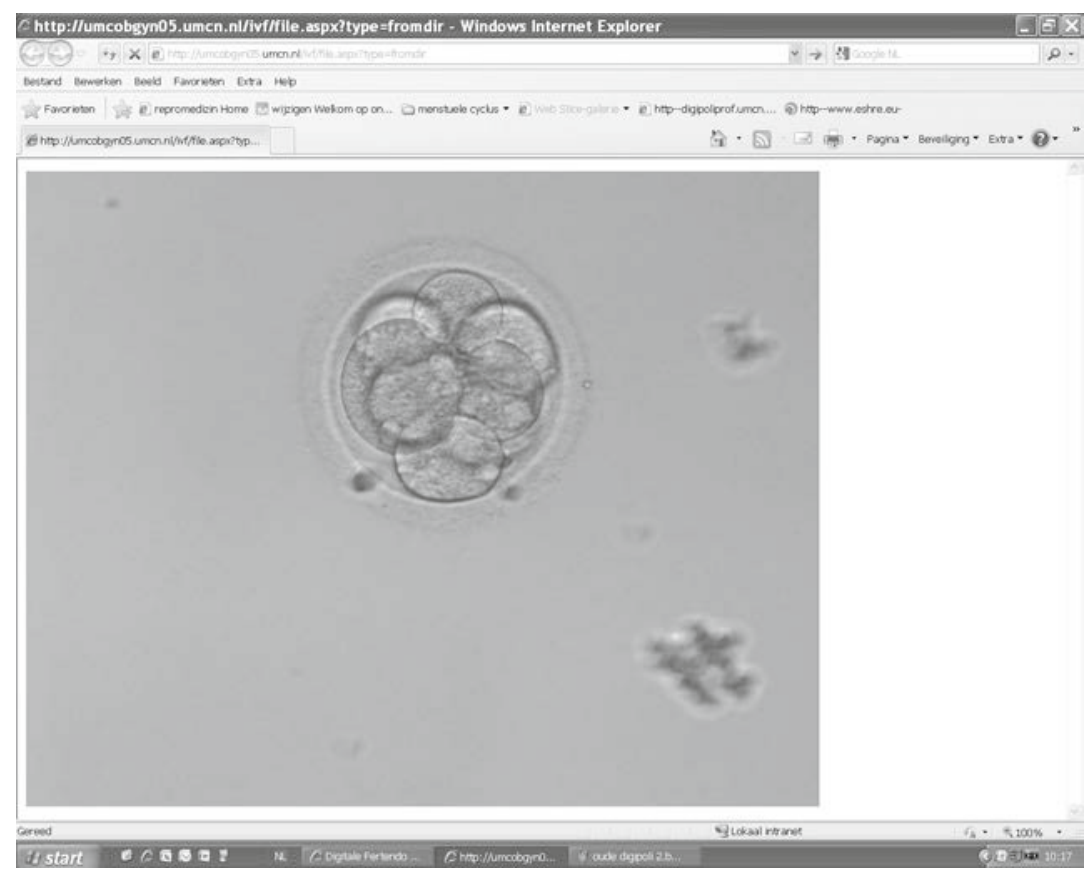

Figuur 3 Het resultaat van de bevruchting, een embryo, kunnen patiënten thuis bekijken. 
echter evenmin nadelige effecten gevonden op angst en depressie. ${ }^{6}$

\section{Elektronisch patiëntendossier}

Het elektronisch patiëntendossier is een beveiligde omgeving waar patiënten en professionals medische gegevens kunnen inzien. Inzage in de eigen medische gegevens wordt gezien als de belangrijkste stap in 'patientcentered care' en 'patient empowerment'.,7 Uit onderzoek is tevens gebleken dat toegang tot het eigen dossier de kennis van patiënten en de communicatie van artsen verbetert. ${ }^{8}$

\section{Online lotgenotencontact}

Een belangrijk onderdeel van de Digitale IVF Poli is online lotgenotencontact. Daartoe is er een forum waarop patiënten contact kunnen leggen met andere patiënten en met zorgverleners.

Een IVF-behandeling is een stressvolle periode. ${ }^{9}$ Het begeleiden van patiënten gedurende deze periode is daarom een belangrijk onderdeel van de dagelijkse zorg. Een IVFcentrum kan echter niet 24 uur per dag zorg leveren. Patiënten die bezig zijn met een IVFbehandeling, hebben behoefte aan informatie en contact, maar een groot deel van hen heeft een baan terwijl het centrum slechts geopend is van 8:0o tot 17:0o uur. ${ }^{10}$ Het internet is voor deze patiënten dan ook een welkome manier om informatie te zoeken en contact op te nemen rondom hun vruchtbaarheidsprobleem. ${ }^{10,11} \mathrm{Om}$ te weten te komen in welke periode patiënten de meeste behoefte hebben aan informatie en contact, is onderzocht op welke momenten de patiënten gedurende de vruchtbaarheidsbehandeling het persoonlijke gezondheidsdossier en het forum gebruikten. Dat bleek voornameijk te gebeuren op die momenten dat de patiënt weinig tot geen contact had met het behandelteam. ${ }^{12}$ Online lotgenotencontact heeft dus wel een meerwaarde in bepaalde periodes van een IVF- of ICSI-behandeling, al is dat nog niet goed uit te drukken in grootheden zoals betere kennis, gedaalde emotionele stress en tevredenheid over de behandeling. ${ }^{6}$
De digitale poli in de praktijk

De eerste versie van de Digitale IVF Poli is online geweest van eind 2004 tot juni 2011. Patiënten die op de wachtlijst stonden voor een IVF- of ICSI-behandeling kregen de mogelijkheid zich aan te melden voor de Digitale IVF Poli door een inschrijfformulier in te vullen. Zij kregen vervolgens van de secretaresse een installatiecertificaat en een unieke inlogcode, gekoppeld aan het ziekenhuisregistratienummer. $\mathrm{Na}$ het installeren van de software op de eigen computer konden patiënten hun eigen gegevens inzien, informatie opzoeken en gebruikmaken van het forum en de chat. Op het forum konden patiënten vragen stellen aan het IVF-team. De verpleegkundige van het IVF-team beantwoordde deze vragen driemaal per dag en zorgde ervoor dat de vragensteller binnen 24 uur antwoord kreeg.

In december 2010 besloot de afdeling Voortplantingsgeneeskunde van het UMC St Radboud de Digitale IVF Poli te laten opgaan in een nieuwe digitale community, www.mijnzorgnet.nl. MijnZorgnet heeft dezelfde opbouw als de oude Digitale IVF Poli, maar is opengesteld voor alle patiënten van de afdeling Voortplantingsgeneeskunde. Deze loggen niet meer in via een persoonlijk certificaat, maar met hun DigiD. Ze kunnen daardoor overal ter wereld inloggen.

\section{MijnZorgnet}

MijnZorgnet heeft tot doel de zorg rondom de patiënt anders te organiseren. De patiënt krijgt een centrale rol in zijn eigen zorgnetwerk en kan zorgverleners, mantelzorgers en medepatiënten uitnodigen deel te nemen aan dat netwerk. MijnZorgnet is de serviceprovider die de patiënt de mogelijkheid geeft zijn zorgnetwerk digitaal vorm te geven. Daarnaast stimuleert MijnZorgnet professionals om samen te werken in 'health communities'.

Iedereen kan op www.mijnzorgnet.nl een profiel maken dat hem in staat stelt deel te nemen aan verschillende communities. Een community is een groep mensen rondom een gezondheidsprobleem. Elke patiënt of zorgverlener is vrij om een community te starten. Er zijn open communities, besloten communities en onzichtbare besloten communities. 


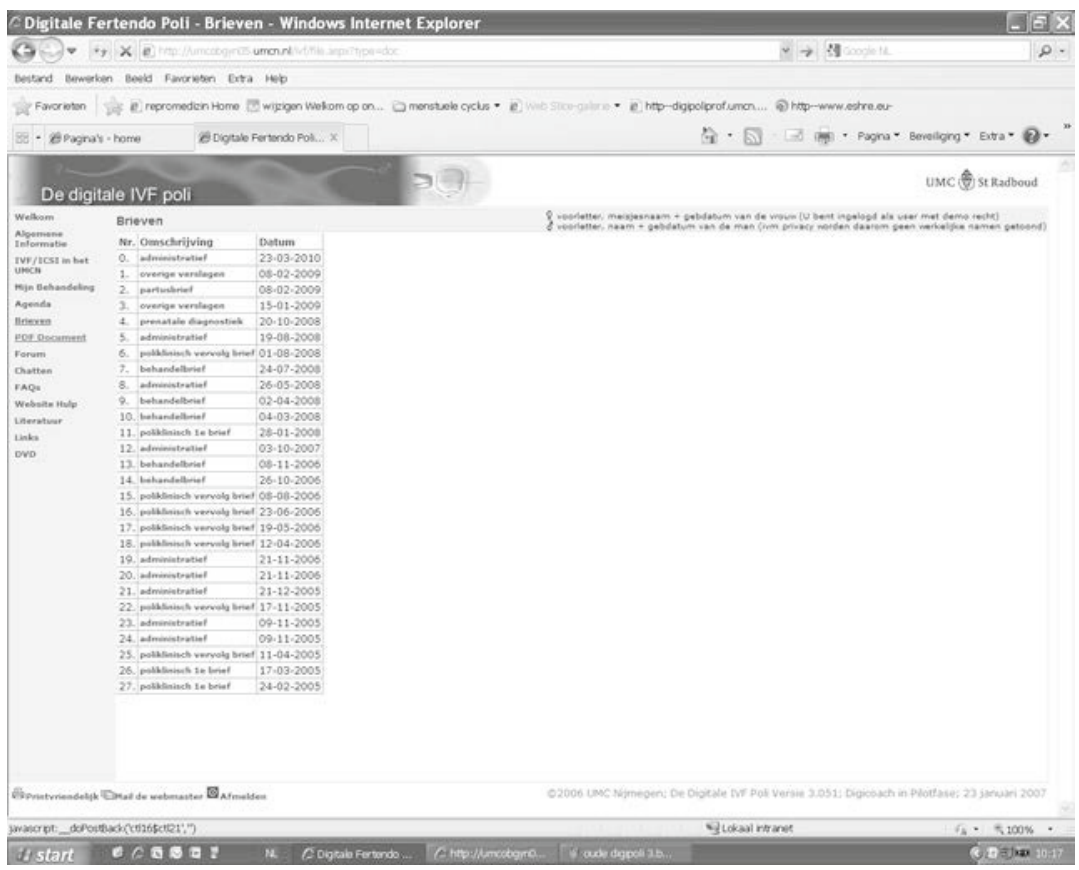

\section{Figuur 4}

Overzicht van alle correspondentie van een patiënt.

Bron: W.S. Tuil

\section{Mijnzorgnet.nl}

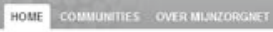

\section{Kom in contact met zorgverleners en medepatiënten!}

G REDENEN OM U AAN TE MELDEN
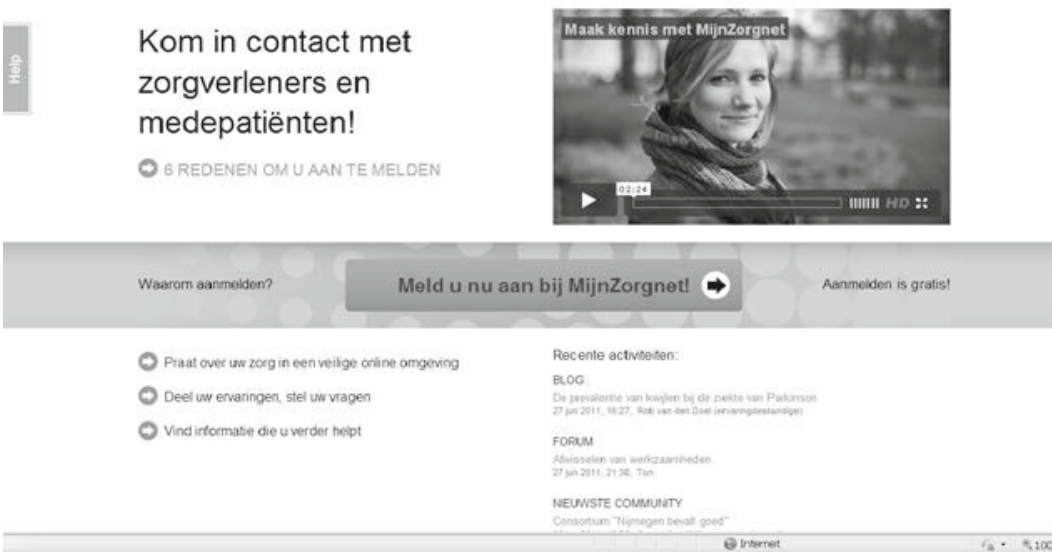

\section{Figuur 5}

Homepage van MijnZorgnet.

Bron: MijnZorgnet 
De community van de afdeling Voortplantingsgeneeskunde is een besloten community. Patiënten die een profiel aanmaken op www.mijnzorgnet.nl kunnen een aanvraag doen om toegelaten te worden tot deze community. De secretaresse controleert of de aanvrager werkelijk patiënt is bij de afdeling en keurt de aanvraag goed of af. Op deze manier wordt de privacy van de patiënten gegarandeerd.

De community bestaat uit verschillende onderdelen:

- de Informatiepagina is zichtbaar voor alle mensen die een account hebben op MijnZorgnet en geeft algemene informatie over de community en hoe aan te melden;

- het Activiteitenoverzicht laat alle activiteiten op de community zien;

- het Blog (figuur 6) is een nieuwspagina waarop een aantal geselecteerde deelnemers nieuwsberichten kan achterlaten;

- op het Forum (figuur 7) kunnen mensen vragen stellen aan elkaar en aan hun profes- sionals, en samen praten over wat hen bezighoudt;

- op het onderdeel Bestanden kunnen bestanden geplaatst worden die belangrijk zijn voor patiënten of professionals, zoals informatiefolders of voorlichtingsfilms;

- op het onderdeel Wiki's staat alle patiënteninformatie over de verschillende behandelingen. Via de wiki, een webtoepassing waarmee deelnemers gezamenlijk kunnen werken aan een document, kunnen patiënten en professionals de informatie aanpassen en up-to-date houden;

- de Ledenlijst geeft een overzicht van alle leden met hun rollen, en biedt de mogelijkheid elkaar berichten te sturen;

- het onderdeel Bekijk uw medische gegevens bevat een koppeling met het elektronische patiëntendossier van het UMC St Radboud. Deelnemers kunnen al hun gegevens inzien, zoals bloeduitslagen, resultaten van de follikelpunctie, foto's van de embryo's die worden teruggeplaatst, en brieven die hun behandelaars geschreven hebben aan andere zorgverleners.

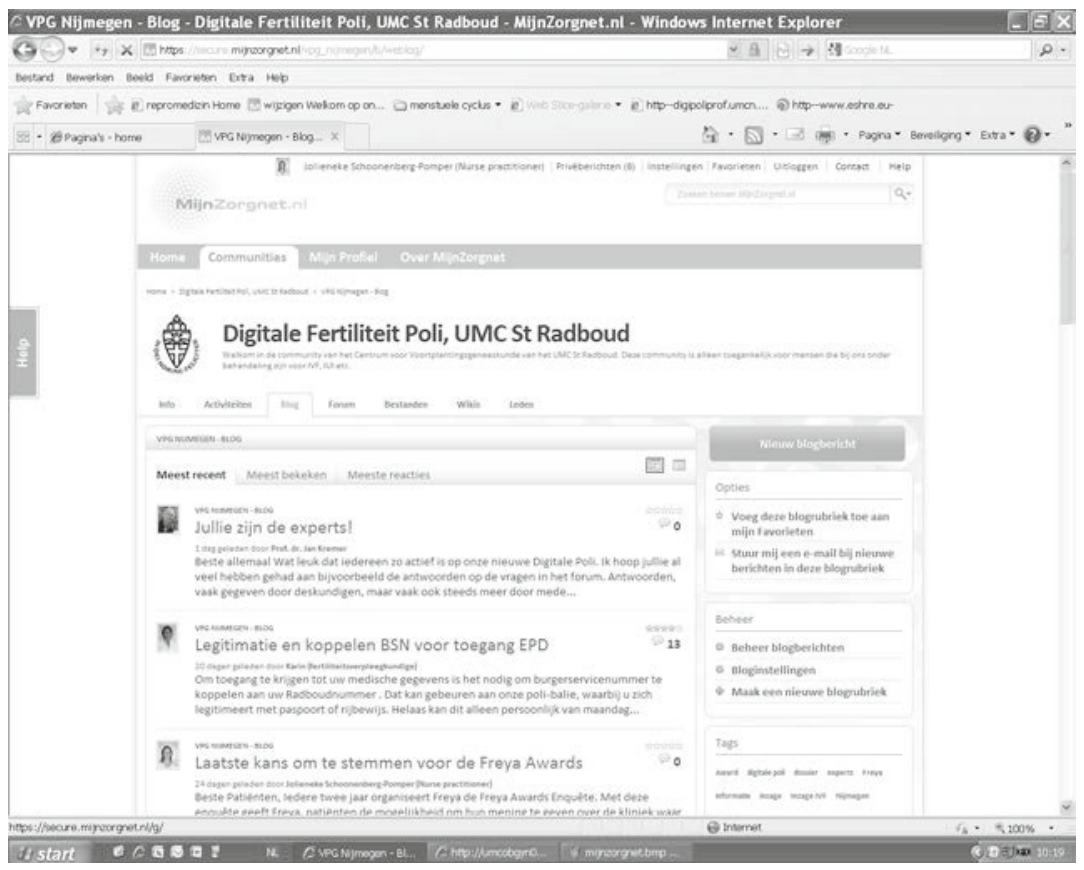

Figuur 6

Overzicht van de blogpagina. 


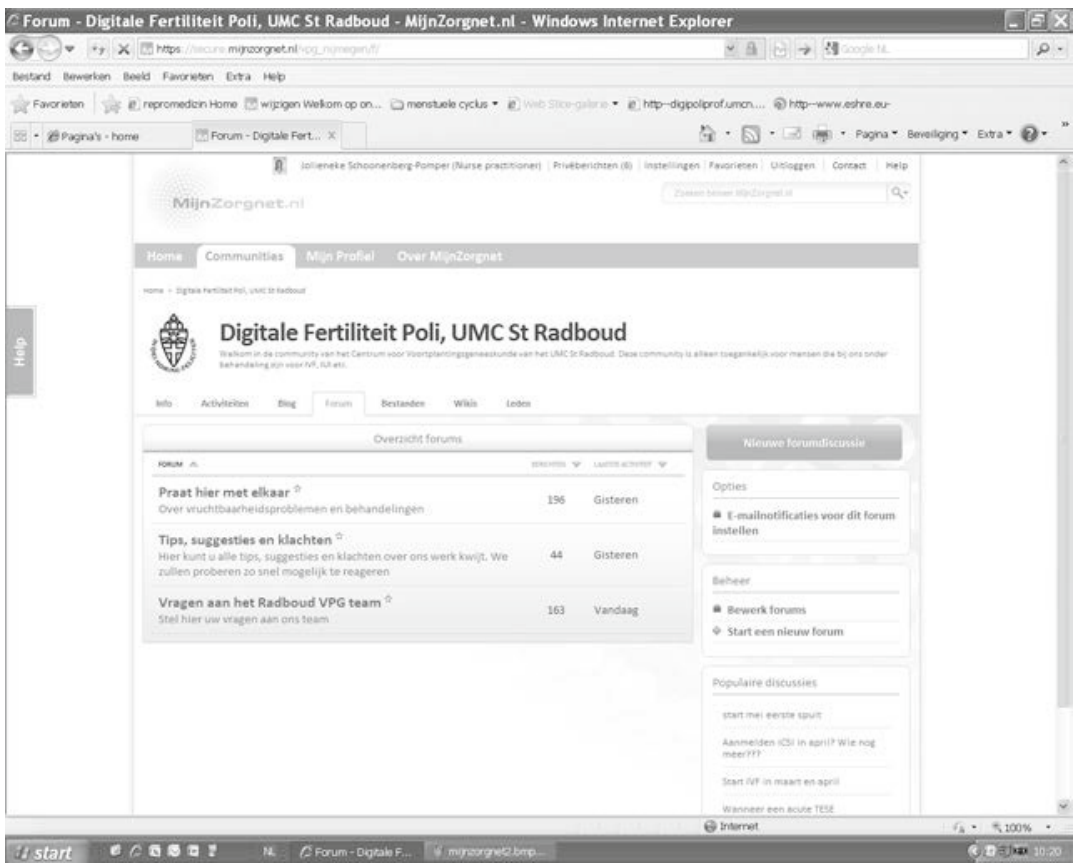

Figuur 7

Overzicht van het forum.

Bron: MijnZorgnet

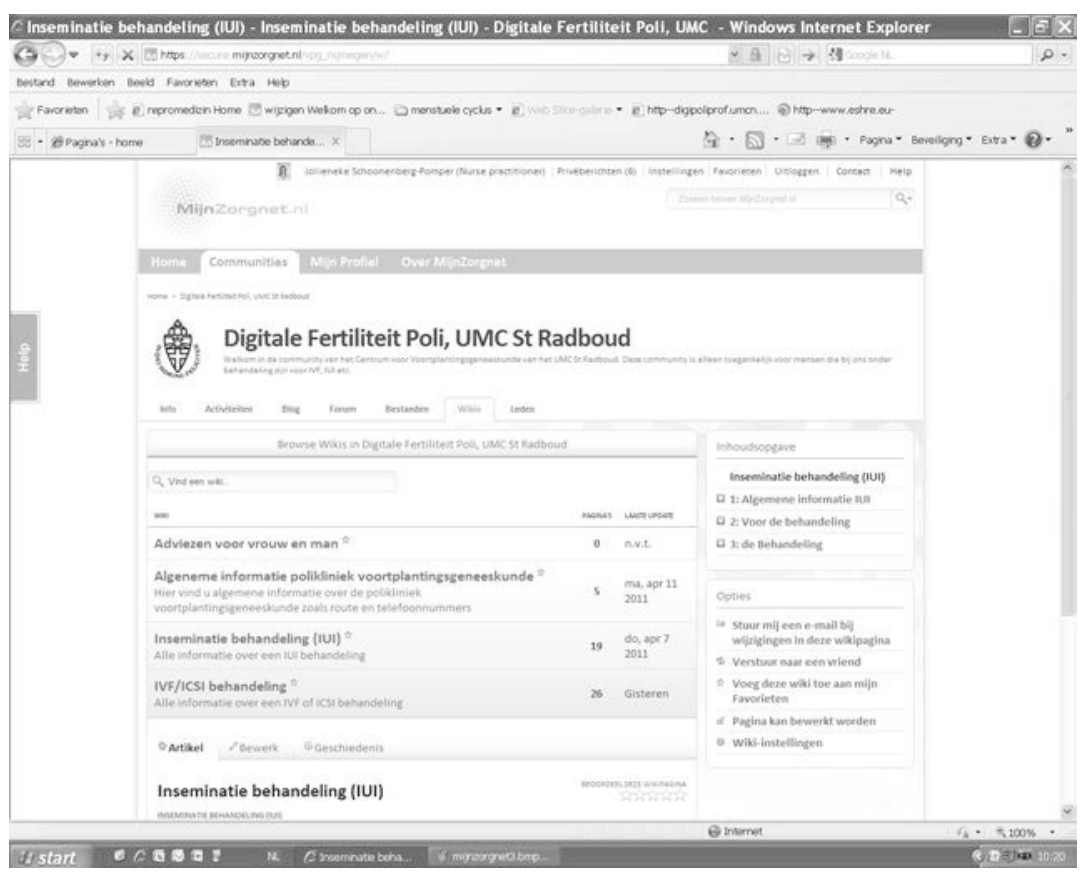

Figuur 8

Overzicht van de verschillende wiki's.

Bron: MijnZorgnet 
MijnZorgnet blijft nieuwe applicaties ontwikkelen om de 'patient empowerment' en de coördinatie van de zorg te bevorderen. Het is de bedoeling dat de patiënt eind 2011 zijn eigen zorgnetwerk kan starten en daarvoor verschillende zorgverleners kan uitnodigen, zoals zijn huisarts, zijn gynaecoloog en zijn fysiotherapeut. Het idee daarachter is dat de patiënt zijn zorgverleners met elkaar in contact brengt, zodat de zorg beter afgestemd kan worden.

\section{Een succes!}

De Digitale IVF Poli van het UMC St Radboud begon als het idee van één persoon en is uitgegroeid tot een regulier onderdeel van de zorg waarvan alle patiënten in het UMC St Radboud gebruik kunnen maken. MijnZorgnet biedt zelfs alle patiënten en professionals in Nederland de mogelijkheid hun eigen digitale poli te starten. Een dergelijk project staat of valt natuurlijk bij de inzet van een goed projectteam, waarin naast de patiënt ook alle professionals rondom een bepaalde patiëntengroep vertegenwoordigd zijn.

\section{Literatuur}

1 Eysenbach G, Diepgen TL. Patients looking for information on the Internet and seeking teleadvice: motivation, expectations, and misconceptions as expressed in e-mails sent to physicians. Arch Dermatol 1999;135(2):151-6.

2 Institute of Medicine. Crossing the quality chasm: A new health system for the twenty-first century. Washington: National Academy Press, 2001.
3 Berwick DM. A user's manual for the IOM's 'Quality Chasm' report. Health Aff (Millwood) 2002;21(3):80-90.

4 Funnell MM, Anderson RM, Arnold MS, Barr PA, Donnelly M, Johnson PD, et al. Empowerment: An idea whose time has come in diabetes education. Diabetes Educ 1991;17:37-41.

5 Anderson RM, Funnell MM, Barr PA, Dedrick RF, Davis WK. Learning to empower patients: Results of professional education program for diabetes educators. Diabetes Care 1995;14:584-90.

6 Tuil WS, Verhaak CM, Braat DDM, Vries Robbé PF de, Kremer JAM. Empowering patients undergoing in vitro fertilization by providing internet access to medical data. Fertil Steril 2007;88(2): 361-8.

7 Eysenbach G, Jadad AR. Evidence-based patient choice and consumer health informatics in the internet age. J Med Internet Res 2001;3(2):E19.

8 Ross SE, Lin CT. The effects of promoting patient access to medical records: a review. J Am Med Inform Assoc 2003;10(2):129-38.

9 Verhaak CM, Smeenk JM, Evers AW, Kremer JA, Kraaimaat FW, Braat DD. Women's emotional adjustment to IVF: a systematic review of 25 years of research. Hum Reprod Update 2007;13(1):2736.

10 Haagen EC, Tuil W, Hendriks J, Bruijn RP de, Braat DD, Kremer JA. Current Internet use and preferences of IVF and ICSI patients. Hum Reprod 2003;18(10):2073-8.

11 Weissman A, Gotlieb L, Ward S, Greenblatt E, Casper RF. Use of the internet by infertile couples. Fertil Steril 20oo;73(6):1179-82.

12 Tuil WS, Selm M van, Verhaak CM, Vries Robbé PF de, Kremer JA. Dynamics of Internet usage during the stages of in vitro fertilization. Fertil Steril 2009;91(3):953-6. 